\title{
Health-related quality of life in young people: the importance of education
}

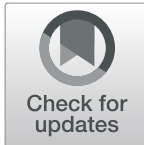

Marta Gil-Lacruz ${ }^{1 *}$ (D) Ana Isabel Gil-Lacruz² (D) and María Luisa Gracia-Pérez ${ }^{3}$ (D)

\begin{abstract}
Background: The concept of health-related quality of life and education integrates the bio-psychosocial perspective of health and the multidimensional potentialities of education for wellbeing. This present work is especially relevant to young people because understanding the interaction between health and education can facilitate the design of preventive policies. The research examines the way in which the educational level of young people from an urban district in the city of Zaragoza (Casablanca) has an influence on their health-related quality of life (HRQOL).

Methods: A cross sectional survey was undertaken in the Casablanca district of Zaragoza (Spain). Participants were not randomly selected; their numbers reflected the areas where they lived with respect to age and sex distribution. It comprised 122 boys and 122 girls, aged between 16 and 29, living in the neighbourhood are: Viñedo Viejo, Las Nieves and Fuentes Claras. These three residence zones are markedly different in terms of socioeconomic composition. The questionnaire included the following information: socioeconomic characteristics (sex, age, educational level, employment status, residence zone), an assessment of health (health problems, diagnosis and medication in the last 2 weeks) and HRQOL (WHOQOL-BREF dimensions: mental health; physical health; social relations; and environment). ANOVA and four regression models were used to assess the role, direction and intensity of educational level on HRQOL.

Results: The results show that the higher the level of education, the better the level of HRQOL. The biggest impact of education was on the mental health dimension, but this influence was modulated by sex and residence zone. The value of the interaction of education and residence zone was more significant than educational level alone. HRQOL of girls is more sensitive to education, being a student and residence zone than the HRQOL of boys.
\end{abstract}

Conclusions: The dimensions of HRQOL are influenced by educational level. The influence is greatest among girls and the youngest members of the poorest area of the district. Public authorities should contemplate the development of an equitable education system from the beginning of the life cycle as a public health strategy.

\section{Introduction}

Health-related quality of life (HRQOL) is a multidimensional concept that includes domains related to physical, mental, emotional, and social functioning [1]. The development of these domains depends on a set of socioeconomic factors in which educational level has an important role. Education implies learning: knowledge,

\footnotetext{
*Correspondence: mglacruz@unizar.es

'Department of Psychology and Sociology, Health Science Faculty, Domingo Miral s/n, 50009 Zaragoza, Spain

Full list of author information is available at the end of the article
}

behaviours, skills and attitudes that can influence health and wellbeing $[2,3]$.

Improvements in the education system lead to a greater understanding of health issues and better health choices $[4,5]$. At the same time, the living conditions and health status of young people (an objective aspect of quality of life) have an impact on their educational and employment possibilities [6, 7]. The World Health Organization [8] believes that good health is both a right of individuals and a resource for societies.

(c) The Author(s). 2020 Open Access This article is licensed under a Creative Commons Attribution 4.0 International License, which permits use, sharing, adaptation, distribution and reproduction in any medium or format, as long as you give appropriate credit to the original author(s) and the source, provide a link to the Creative Commons licence, and indicate if changes were made. The images or other third party material in this article are included in the article's Creative Commons licence, unless indicated otherwise in a credit line to the material. If material is not included in the article's Creative Commons licence and your intended use is not permitted by statutory regulation or exceeds the permitted use, you will need to obtain permission directly from the copyright holder. To view a copy of this licence, visit http://creativecommons.org/licenses/by/4.0/. The Creative Commons Public Domain Dedication waiver (http://creativecommons.org/publicdomain/zero/1.0/) applies to the data made available in this article, unless otherwise stated in a credit line to the data. 
The close relationship between education and health is indisputable at both the individual and public investment level [9]. Health improvements increase access and equity to current educational institutions that are characterised by diversity (students age and ethnical origin, teaching styles, contents and values, curricula requirements, and so on).

Targeted public policies on education may not only have a positive impact on the education level of our young citizens, they could also lead to an improvement on HRQOL. This implies gaining a better understanding of the link between HRQOL and the level of education. This, in turn, requires the consideration of people's values and experiences related to living conditions, integrating the opinion of those who share the same conditions. This article aims to address this international challenge from a local perspective, the natural context of youth development. The study aims to analyse the relationship between educational level and HRQOL in a sample of urban youth by assessing the impact of socioeconomic variables such as sex, employment status and place of residence.

In a European study of 21,590 children and adolescents, sex was shown to be an important predictor of HRQOL; at a young age both sexes have a similar level, but, with increasing age, the HRQOL of girls is worse than boys [10]. The work by Michel was based on a European sample using the KIDSCREEN-52 questionnaire [10], but the same trend has been reported in studies that have employed other HRQOL instruments, such as the generic EQ-5D [11] and health perceived status instruments like the Short Form Health Survey [12-14]. These differences could be found in diverse indicators for example, stress and accidents are more common among boys and anxiety is more prevalent among girls [15]. In fact, these differences persist through the life span. In the study of Burström et al. [11], HRQOL index was significantly lower in all age-groups for women. Besides, women suffered the greatest increase on anxiety/ depression and pain/discomfort (measured with generic EQ-5D, 1998 and 2002 waves).

The exact cause of these health inequalities is open to debate. Socioeconomic variables influence on health differences among young people requests a deeper research [16]. Income, occupation, residence and level of education are still indicators of social class; educational level is related to occupation (access to higher paid, more stable employment) and earnings [17].

Darias [18] listed interactions between educational level and the dimensions of health. First one: Education, family and socioeconomic inheritance span the life cycle and have an impact on the present and future resources of the individual (health status, social networks, living conditions etc.). Second one: A higher educational level allows better access and use of health resources, better understanding of health information and the adoption of healthier lifestyles [19]. Third one: Health problems in childhood are associated with lower academic performance and subsequent health complications that can lead to employment difficulties.

The link among educational level and health with other variables such as sex and age, can adopt an accumulative effect along the life cycle. These interactions lead us to hypothesize that health inequalities increase with age [20].

A variety of theoretical models have aimed to examine the relationship between education and health [21]:

- From a materialistic perspective, the negative consequences of deprivation and social exclusion suggest that a lower level of education translates into worse health indicators; therefore the materialistic perspective includes the social effects of poverty, for example, differences in life expectancy $[22,23]$.

- In formal education, credentialism (the possession of titles and certificates awarded by the education system) is manifested in better employment opportunities that result in a better quality of life [24]. One of the functions of the education system should be to reduce the health and education gaps that generate the initial social inequalities.

- The influence model of events throughout the life cycle argues that education allows for development of cognitive skills related to personal care [25]. The circumstances in which people live have an obvious impact on health [16].

- The causal selection model focuses on explaining how health complications from childhood are associated with poor academic and work performance. Health is seen as a determining factor for social class - not the other way around [20].

These models of analysis are based on a definition of health that transcends illness and the prevalence of risk behaviours. Educational level is an indicator of social class that compromises the opportunities of personal and social development [17]. The study of HRQOL among young people should not be confined to the field of epidemiology and mental health. The level of health is also impacted by values, representations, beliefs and attitudes [26]. The analysis of the classic indicators of public health (e.g. morbidity, mortality, life expectancy etc.) should be complemented by the study of other factors related to the individual and collective functioning of the person $[27,28]$. This scientific literature emphasizes two important dimensions: First one, cognitive, physical and social functioning which refers to the satisfaction 
generated by positive relationships, the ability to be autonomous, a healthy lifestyle and good mental and physical health. Second one, personal care and emotional wellbeing which include the possibility of learning and acquiring knowledge, the development of personal skills and feelings of happiness and selfesteem, the assessment of physical condition and socioeconomic position [27, 28].

This approach sees the study of HRQOL as a multidimensional concept that integrates physical, psychological and social factors [29]. This concept has been used during the last decade to prioritise medical care needs, measure the degree of wellbeing, and assess the outcomes of clinical treatments [30]. It is also gaining popularity in studies of adolescents and young people, aimed at diagnostic and preventive evaluation [31-34].

In 1991, the World Health Organization [35] led an international project to integrate debates on the multidisciplinary nature of the definition of health-related quality of life. It was intended to emphasise its objectivesubjective and individual-social nature and to be contextualised in countries with different levels of industrialisation, health system coverage and cultural diversity (the role of the family, perception of time or religious belief). The term 'Health-Related Quality of Life' (HRQOL) was agreed as the individual's perception of their own vital position, in the context of their culture and value system and in relation to their goals, expectations, standards and interests [36].

This definition is intended to provide a generic measure and contemplates the situation of the person within their reference group [37]. There were six dimensions in the original instrument: physical health; psychological functioning; independence; social relations; environment; and spirituality.

A number of questionnaires inspired by the WHO instrument have been utilised with young people [36, 38]. The longest version (100 items) was used by Cilga [39], who studied the perception of HRQOL among young residents of a vulnerable neighbourhood in Turkey. They found that the physical and psychological functioning of the participants was in need of improvement - $41 \%$ of those interviewed said that they had problems coping with pain.

The short version of the WHOQOL (26 items) has also been widely employed. Exponents include projects undertaken in Thailand, New Zealand and China [4042]. However, some items, such as 'Live without Pain' and 'Confidence in Medication' were not considered as relevant.

From a comparative and international perspective, age is a source of diversity [43]. Adults prioritise the environment, social support, transportation, the health system and the feeling of being physically fit; younger people give more importance to positive expectations for the future, social relationships and finding an interesting job [43].

The scientific literature focuses on the importance of the relational and environmental dimensions in research on young people and HRQOL [29]. Examples include studies on Ethiopian street youth $[44,45]$ and student mobbing [46].

As the study of HRQOL involves comparison of reference groups, an open line of research is found in the generalisation of these studies to other types of samples of young people in different socioeconomic and health conditions. A project in Bangladesh [47] analysed the impact of determinants of health such as nutrition and place of residence on the quality of life of adolescents; the results of these types of works have highlighted the impact of contextual variables on the perceived satisfaction of young people [48].

As a context, the school has received considerable attention: HRQOL was directly related to the quality of the educational environment, institutional satisfaction and academic level [48]. Similar results were reported in the university context, where satisfaction with the institution has been directly associated with academic achievement [49]. The feeling of belonging to the educational institution and support offered by the family and peers improves the perception of quality of life $[50,51]$.

Education seems to have a significant effect on HRQOL; Baumann et al. [52] undertook a study with 355 students from Luxembourg, Belgium and Romania. The psychological dimension of quality of life was positively associated with academic skills and knowledge regarding employability in Luxembourg and Romania, but not in Belgium. It is clear that more research is required in this area.

\section{Method}

This current work focuses on the environment, contextualising the relationship between education and the dimensions of HRQOL in a local community. The main hypothesis is that the higher the level of education, the better the level of HRQOL. However, it is expected that these results will be mediated by quality of life dimensions and sex.

\section{Sample}

Neighbourhoods are the residential units in which young people develop, psychosocial interventions are planned and community participation takes place. The district of Casablanca (Zaragoza, Spain) was chosen for this work due to its socioeconomic diversity and easy access to health resources. Its diversity can be seen in the condition of housing (year of construction, type of construction, facilities such as lifts, gardens etc.) and the 
socioeconomic characteristics of the residents (occupation, income, age, origin etc.). Furthermore, the urbanisation of the district has resulted in these differences being reflected in three clearly defined areas that are separated by roads, a railway line and a canal.

The three neighbourhoods selected for the study correspond to the socioeconomic stratification of the community: Fuentes Claras fits the upper middle-class residential model; Viñedo Viejo is the traditional lowermiddle/working-class area; and Las Nieves is predominantly upper-middle class.

The age range was chosen as many institutions that work with young people (for example, the Spanish Youth Institute) consider 'young people' as individuals under the age of 30 and health surveys have a minimum participation age of 16. Assuming a normal distribution of the variables, an $\alpha$ risk of $10 \%$, a $\delta$ (error) of $5 \%$ and the sex distribution of the population aged 16 to 29 years in Casablanca area, the theoretical sample size was $n=240$ (Fig. 1). The sample also reflected the socioeconomic distribution of the target population (Table 1).

Participants were recruited at various locations in the district. $17.2 \%$ were interviewed in their schools, $4.5 \%$ at the Casablanca Youth Centre, 20.9\% at their homes and $57.4 \%$ in the streets, parks and public places.

Previous to the field research, information about the survey (goals, topics, ethic norms commitment, public funds, researchers contact and so on) was distributed to the neighbourhood by mail boxing. Research team members also visited Casablanca Civic Center, Social Center, Youth Center and the two High Schools of the district. We conducted several interviews with their professionals and directors. All actions were accepted and approved by participants.

Key infomants who collaborate with the survey implementation were: principal researcher and three researchers (Research group: Wellbeing and Social Capital ref. S.51, University of Zaragoza, Spain), two directors of Casablanca Youth Center, the social worker of Health

$$
n=\frac{\mathrm{N} * \mathrm{Z} \alpha^{2} * \mathrm{p} * \mathrm{q}}{\mathrm{d}^{2} *(\mathrm{~N}-1)+\mathrm{Z} \alpha^{2} * \mathrm{p} * \mathrm{q}}
$$

$\mathrm{N}$ (population: young people living in Casablanca) $=2,129$

$\mathrm{Z}_{\alpha}{ }^{2}=1.645^{2}$ (if confidence level 90)

$\mathrm{p}$ (male proportion $)=0.4814$

$\mathrm{q}$ (female proportion) $=0.5186$

$\mathrm{d}($ margin of error $)=0.05(5 \%)$

Fig. 1 Formula for the sample size determination (n). N (population: young people living in Casablanca) $=2129 . Z_{a}{ }^{2}=1.645^{2}$ (if confidence level 90). p (male proportion) $=0.4814$. q (female proportion $)=0.5186 . \mathrm{d}($ margin of error $)=0.05(5 \%)$
Community Center, three directors of High Schools, five students in training period at Zaragoza University. All these agents shared the same information provided by the principal researcher.

We informed previously to our survey agents about the convenience of keeping the residence zone composition and the population distribution. Two facts were helpful. First one, an important group of young interviewed were alumni of targeted High Schools (located in distant places of the neighbourhood). The source of diversity is important because of the number of interviews and main activity (studying) of the youth at Casablanca. Second one, when training students at Zaragoza University were integrated into the research field, we had information about the number of interviews completed and the need to explore specific zones.

Participation seemed to depend on the location of the interview; for example, in the school and local youth centre, the response rate was $90 \%$, compared with a rate of $70 \%$ in public places.

\section{Instrument}

This study is part of a wider research project that was conducted in Casablanca to analyse HRQOL and lifestyles. From the original survey, the statistical exploitation of the following thematic blocks was selected:

- Socioeconomic characteristics: sex, age, marital status, employment status and educational level. Following the criteria of the International Standard Classification of Education [54], educational level was categorised as: no studies; primary; secondary and university (post-secondary education). Educational level was considered as an explanatory variable, the age of the sample meant that all participants could have had secondary or university education. Secondary was defined as a dummy variable that informs us if the individual has reached secondary (1) or university (0) education. The main problem with the age group is that many people were too young to have had access to university. For this reason, the category Student was introduced, as unemployment in the area is low, working and unemployed people were grouped together as an active population.

- Assessment of health: Health problems, diagnosis by the health service and medication in the last 2 weeks. The wording of these questions was the same as those of the Spanish National Health Survey to allow comparison. The answers to the questions are 'Yes' or 'No'.

- Health-related quality of life: measured by the WHOQOL-BREF [38]. The selection of this instrument was due to its international character and 
Table 1 Population and sample composition by area of residence and gender

\begin{tabular}{|c|c|c|c|c|c|c|c|c|}
\hline \multirow[b]{2}{*}{ Residence } & \multicolumn{4}{|c|}{ Casablanca youth population $^{a}$} & \multicolumn{4}{|c|}{ Sample distribution } \\
\hline & Males (N) & Females (N) & Total (N) & Total \% & Males $(n)$ & Females $(n)$ & Total $(n)$ & Total $\%$ \\
\hline Viñedo Viejo & 615 & 662 & 1277 & $60 \%$ & 79 & 72 & 151 & $62 \%$ \\
\hline Las Nieves & 205 & 221 & 426 & $20 \%$ & 12 & 28 & 40 & $16 \%$ \\
\hline Fuentes Claras & 205 & 221 & 426 & $20 \%$ & 31 & 22 & 53 & $22 \%$ \\
\hline Total & 1025 & 1104 & 2129 & $100 \%$ & 122 & 122 & 244 & $100 \%$ \\
\hline
\end{tabular}

$N$ Population size, $n$ Sample size

${ }^{a}$ The information provided about sex is the district distribution. The information about residence zone is orientative, because district data are not desegregated at this level. We have used previous studies to calculate it [53]

prior use with young people. The instrument was validated by Krägeloh et al. [41] with a sample of students; it was found to have a good level of reliability: Cronbach's Alpha for the overall scale was 0.89 . The criterion-related validity (the correlation of item and domain scores with the score of each of the two global items) and ordinal confirmatory factor analyses also gave positive results.

The questionnaire integrates two generic items about the general perception regarding HRQOL, with four dimensions: physical (7 items; minimum score: 7; maximum score: 35), mental (6 items, minimum score: 6 ; maximum score: 30$)$, social (3 items, minimum score 3 , maximum score 15 ), and environment (8 items, minimum score 8 ; maximum score 40). The items have a score from 1 (very negative) to 5 (very positive) on a Likert scale. All the variables are quantitative: higher values imply better health-related quality of life. Further information about scores and psychometric proprieties are provided by Skevington, Lotfy and O'Connell research [38].

\section{Empirical strategy}

The descriptive results of the dependent and explanatory variables were analysed. As dependent variables we have selected the dimensions of WHOQOL-BREF (physical, mental, social, environment), and also their aggregation in one variable. As explanatory variables we considered: sex, age, educational level, employment status, residence zone, and self-assessment of health (this last one, used only on ANOVAs). We have selected three levels of $p$ value $(<0.001<0.01,<0.05)$ in order to explain the significance of the variables in the ANOVAs analysis.

ANOVAs and post hoc Tukey tests were used to identify differences in means of dependent variables among groups created by values of independent variables. Four equation models based on regression analysis were designed to identify differential predictors of HRQOL between girls and boys. Given that the dependent variables are quantitative, Ordinary Least Squares (OLSQ) estimations were used to report data in terms of regression coefficients (STATA command: regress, $\mathrm{mfx}$ ). OLSQ is a type of linear least squares method for estimating the unknown parameters. Regarding the assumption of linearity, meanwhile our dependent variables are quantitative our explanatory variables are dummy variables, which meet the assumption of linearity by definition, because they create two data points, which define a straight line. The codification of educational level in dummy variables is meaningful and straightforward. Regarding the significance of estimated parameters, these coefficients are useful to indicate how responsive the state of health is to a change in educational level. Independent estimations were calculated for boys and girls to determine if education plays a different role (in terms of sense or intensity) over their health. Four independent models were designed: Model 1 only considers educational level as an explanatory variable; Model 2, takes into account the fact that the participant may still be a student and could reach a higher educational level - the interaction of Secondary*Student (a variable that takes the value 1, if the individual has reached secondary education and is a student, 0 otherwise) has been included; Model 3 controls for the area of residence as a proxy of social status - the interaction of Secondary*ViñedoViejo (a variable that takes the value 1 , if the individual has reached secondary education and lives in Viñedo Viejo, 0 otherwise) has been included; Finally, Model 4 considers both student status and residence zone - the interactions Secondary ${ }^{*} S$ tudent and Secondary*Student*ViñedoViejo (a variable that takes the value 1 , if the individual has reached secondary education, is a student and lives in Viñedo Viejo and, 0 otherwise) has been included. In OLSQ regressions we have not included neither age nor selfassessment of health as independent variables: age because the estimated coefficients are not statistically significant, so we do not explain them among main results, and self-assessment of health because the estimated coefficients are omitted by collinearity problems. These results are provided in the supplemental material.

Interactions are often considered to control statistically a situation in which there is a simultaneous influence among variables. Is it possible that the educational effect on HRQOL dimensions for young people living in Viñedo Viejo is different than for those living in other 
residence zones? Or will it be pretty much the same? Interactions answer these questions. In this research we consider the interaction of educational level with employment status and residence zone.

SPSS18.00 and STATA 13.0 were used for statistical analysis.

\section{Results}

The sample was made up of 244 individuals between the ages of 16 and 29 years old- Sample was equally distributed by sex: 122 boys and 122 girls were interviewed. One hundred fifty-one were living at Viñedo Viejo, 40 at Las Nieves and 53 at Fuentes Claras. The mean age of the sample was 21.32 years old (standard deviation = 3.73 , mode $=22$ ).

The vast majority of the participants were unmarried (95.9\% boys, $94.3 \%$ girls) and lived with their parents in four-member households. (Tables 2 and 3 show the main descriptive statistics).

$48 \%$ of the sample had achieved secondary studies and $44 \%$ of interviewers had achieved university studies. $56 \%$ of the sample is studying as a main activity. $61 \%$ of the girls and $52 \%$ of the boys interviewed are studying. $44 \%$ of the boys and $32 \%$ of the girls are working.

ANOVAS and post hoc Tukey results were (see Table 2):

- Sex: girls had a more negative perception of the Physical $(p<0.01)$, Mental $(p<0.05)$, and Environment $(p<0.05)$, dimensions of HRQOL than boys.

- Age: there were statistically significant differences regarding perception of Environment $(p<0.01)$ : older participants gave a more negative evaluation.

- Educational level: this variable has a statistical significant impact on all HRQOL dimensions: Physical $(p<0.01)$, Mental $(p<0.05)$, Relations $(p<$ $0.05)$, and Environment $(p<0.01)$.

- Employment status: there are statistical significant differences among employment status and HRQOL dimensions: Physical $(p<0.05)$, Mental $(p<0.05)$, Relations $(p<0.05)$, and Environment $(p<0.05)$.

Table 2 Descriptive statistics and ANOVAs by health-related quality of life $(n=244)$

\begin{tabular}{|c|c|c|c|c|c|c|c|c|c|}
\hline \multicolumn{2}{|l|}{ Variables } & \multicolumn{2}{|l|}{ Physical Health } & \multicolumn{2}{|l|}{ Mental Health } & \multicolumn{2}{|l|}{ Relations } & \multicolumn{2}{|l|}{ Environment } \\
\hline & $\mathrm{N}$ & Mean and SD & $\begin{array}{l}\text { Anova } \\
p \text {-value }\end{array}$ & Mean and SD & $\begin{array}{l}\text { Anova } \\
p \text {-value }\end{array}$ & Mean and SD & $\begin{array}{l}\text { Anova } \\
p \text {-value }\end{array}$ & Mean and SD & $\begin{array}{l}\text { Anova } \\
p \text {-value }\end{array}$ \\
\hline Sex & & & 0.078 & & 0.002 & & 0.469 & & 0.037 \\
\hline Male & 122 & $28.17 \pm 3.33$ & & $23.79 \pm 2.85$ & & $11.87 \pm 2.02$ & & $30.13 \pm 4.04$ & \\
\hline Female & 122 & $27.35 \pm 3.74$ & & $22.55 \pm 3.29$ & & $11.68 \pm 2.09$ & & $29.03 \pm 4.08$ & \\
\hline Age & & & 0.653 & & 0.565 & & 0.498 & & 0.097 \\
\hline 16 to 18 & 66 & $27.63 \pm 3,80$ & & $22.94 \pm 3.36$ & & $11.58 \pm 2.11$ & & $30.39 \pm 4.46$ & \\
\hline 19 to 24 & 127 & $27.96 \pm 3.38$ & & $23.38 \pm 3.10$ & & $11.92 \pm 2.08$ & & $29.50 \pm 3,94$ & \\
\hline 25 to 29 & 51 & $27.45 \pm 3.72$ & & $22.96 \pm 2.93$ & & $11.61 \pm 1.91$ & & $28.74 \pm 3.85$ & \\
\hline Educational level & & & 0.069 & & 0.003 & & 0.002 & & 0.081 \\
\hline Primary & 19 & $26.32 \pm 4.52$ & & $22.37 \pm 4.15$ & & $10.63 \pm 2.44$ & & $30.17 \pm 5.19$ & \\
\hline Secondary & 118 & $27.57 \pm 3.56$ & & $22.60 \pm 2.92$ & & $11.49 \pm 2.03$ & & $28.97 \pm 4.02$ & \\
\hline University & 107 & $28.24 \pm 3.30$ & & $23.94 \pm 3.01$ & & $12.25 \pm 1,90$ & & $30.15 \pm 3.90$ & \\
\hline Employment status & & & 0.044 & & 0.009 & & 0.008 & & 0.020 \\
\hline Autonomous worker & 15 & $27.67 \pm 4.11$ & & $23.53 \pm 3.13$ & & $12.60 \pm 2.06$ & & $29.33 \pm 4.38$ & \\
\hline Employment & 77 & $27.51 \pm 3.50$ & & $22.79 \pm 2.93$ & & $11.63 \pm 1.97$ & & $28.78 \pm 4.04$ & \\
\hline Unemployment & 13 & $25.54 \pm 3.52$ & & $20.77 \pm 3.34$ & & $10.00 \pm 2.48$ & & $27.31 \pm 4.21$ & \\
\hline Student & 137 & $28.21 \pm 3.45$ & & $23.63 \pm 3.12$ & & $11.96 \pm 1.98$ & & $30.32 \pm 3.93$ & \\
\hline Housewife & 2 & $24.00 \pm 4.24$ & & $20.50 \pm 0.70$ & & $11.50 \pm 0,70$ & & $28.00 \pm 7.07$ & \\
\hline Residence zone & & & 0.198 & & 0.087 & & 0.109 & & 0.001 \\
\hline Viñedo Viejo & 151 & $27.54 \pm 3.44$ & & $22.86 \pm 3.17$ & & $11.59 \pm 2.14$ & & $28.92 \pm 3.94$ & \\
\hline Las Nieves & 40 & $28.69 \pm 3.32$ & & $24.05 \pm 2.88$ & & $12.41 \pm 1.75$ & & $31.50 \pm 4.32$ & \\
\hline Fuentes Claras & 53 & $27.69 \pm 3.99$ & & $23.42 \pm 3.12$ & & $11.92 \pm 1.89$ & & $29.98 \pm 3.88$ & \\
\hline Health problems & & & 0.000 & & 0.001 & & 0.570 & & 0.006 \\
\hline Yes & 53 & $25.86 \pm 3.36$ & & $21.96 \pm 3.50$ & & $11.63 \pm 2.56$ & & $28.21 \pm 4.22$ & \\
\hline Not & 191 & $28.28 \pm 3.44$ & & $23.52 \pm 2.94$ & & $11.82 \pm 1.88$ & & $29.96 \pm 3.98$ & \\
\hline
\end{tabular}


Table 3 Descriptive statistics of the dependent and explanatory variables ( $n=244)$

\begin{tabular}{|c|c|c|c|c|c|}
\hline \multirow[t]{2}{*}{ Variables } & \multirow[t]{2}{*}{ Description } & \multicolumn{2}{|c|}{$\begin{array}{l}\text { Females } \\
\text { (Observations = 122) }\end{array}$} & \multicolumn{2}{|c|}{$\begin{array}{l}\text { Males } \\
\text { (Observations = } \\
122 \text { ) }\end{array}$} \\
\hline & & Mean & SD & Mean & SD \\
\hline \multicolumn{6}{|l|}{ Dependent variables } \\
\hline PhysicalHealth & Seven items. Likert: 1 = nothing; $5=$ strongly agree & 27.35 & 3.7 & 28.17 & 3.3 \\
\hline MentalHealth & Six items. Likert: $1=$ nothing; $5=$ strongly agree & 22.55 & 3.3 & 23.79 & 2.9 \\
\hline Relations & Three items. Likert: $1=$ nothing; $5=$ strongly agree & 11.68 & 2.1 & 11.87 & 2.0 \\
\hline Environment & Eight items. Likert: $1=$ nothing; $5=$ strongly agree & 29.03 & 4.1 & 30.13 & 4.0 \\
\hline Total & Higher score means better health-related quality of life & 88.31 & 12.6 & 92.18 & 13.3 \\
\hline \multicolumn{6}{|l|}{ Explanatory variables } \\
\hline Secondary & $\begin{array}{l}\text { Dummy variable: } 1 \text { if the individual has secondary studies, } \\
0 \text { in case of tertiary studies. }\end{array}$ & 0.56 & 0.5 & 0.57 & 0.5 \\
\hline Student & Dummy variable: 1 if the individual is a student, 0 otherwise & 0.61 & 0.5 & 0.52 & 0.5 \\
\hline Secondary\&Student & $\begin{array}{l}\text { Dummy variable: } 1 \text { if the individual has secondary studies } \\
\text { and is a student, } 0 \text { otherwise. }\end{array}$ & 0.31 & 0.5 & 0.30 & 0.5 \\
\hline ViñedoViejo & Dummy variable: 1 if the individual lives in Viñedo Viejo, 0 otherwise. & 0.59 & 0.5 & 0.65 & 0.5 \\
\hline Secondary\&ViñedoViejo & $\begin{array}{l}\text { Dummy variable: } 1 \text { if the individual has secondary studies and lives in } \\
\text { Viñedo Viejo, } 0 \text { otherwise. }\end{array}$ & 0.32 & 0.5 & 0.39 & 0.5 \\
\hline Secondary\&Student\&ViñedoViejo & $\begin{array}{l}\text { Dummy variable: } 1 \text { if the individual has secondary studies, is a student } \\
\text { and lives in Viñedo Viejo, } 0 \text { otherwise. }\end{array}$ & 0.14 & 0.3 & 0.16 & 0.4 \\
\hline
\end{tabular}

- Health problems: there is empirical evidence that young people with health problems reported lower levels of following HRQOL dimensions: Physical $(p<0.01)$, Mental $(p<0.01)$, and Environment $(p<$ $0.01)$.

Table 4 shows regression coefficients of educational level for the state of health of young women living in Casablanca. In Model 1, there is empirical evidence that health dimensions are determined by education level: the higher level of education, the better the state of health. Mentalhealth is the health dimension most sensitive to educational level, followed by PhsyicalHealth and Relations. The influence of education on MentalHealth is more than double that of Environment. When controlled for educational attendance, Model 2 reveals that having secondary education (rather than university) has a negative impact, with the exception of health as an aggregated measure. In the case of Relations, the estimated coefficient remains stable, but it increases for PhysicalHealth and MentalHealth. Secondary is modulated by Secondary*Student for PhysicalHealth, MentalHealth,

Table 4 Regression coefficients of educational level among young women living in Casablanca $(n=122)$

\begin{tabular}{|c|c|c|c|c|c|c|c|c|c|c|}
\hline & \multicolumn{2}{|c|}{ PhysicalHealth } & \multicolumn{2}{|l|}{ MentalHealth } & \multicolumn{2}{|l|}{ Relations } & \multicolumn{2}{|c|}{ Environment } & \multicolumn{2}{|l|}{ Total } \\
\hline & $\begin{array}{l}\text { Regression } \\
\text { coefficients }\end{array}$ & $p$-value & $\begin{array}{l}\text { Regression } \\
\text { coefficients }\end{array}$ & $p$-value & $\begin{array}{l}\text { Regression } \\
\text { coefficients }\end{array}$ & $\begin{array}{l}\text { Regression } \\
\text { coefficients }\end{array}$ & $p$-value & $\begin{array}{l}\text { Regression } \\
\text { coefficients }\end{array}$ & $p$-value & $\begin{array}{l}\text { Regression } \\
\text { coefficients }\end{array}$ \\
\hline \multicolumn{11}{|l|}{ Model 1} \\
\hline Secondary & -1.463 & 0.03 & -2.165 & 0.00 & -1.235 & 0.00 & -1.017 & 0.17 & -8.563 & 0.00 \\
\hline \multicolumn{11}{|l|}{ Model 2} \\
\hline Secondary & -2.451 & 0.00 & -2.607 & 0.00 & -1.221 & 0.01 & -1.993 & 0.030 & -7.522 & 0.01 \\
\hline Secondary\& Student & 1.859 & 0.04 & 0.811 & 0.29 & -0.029 & 0.96 & 1.789 & 0.073 & -1.885 & 0.52 \\
\hline \multicolumn{11}{|l|}{ Model 3} \\
\hline Secondary & -0.373 & 0.67 & -1.276 & 0.08 & -1.035 & 0.05 & 0.649 & 0.47 & -7.090 & 0.01 \\
\hline Secondary\& ViñedoViejo & -1.886 & 0.04 & -1.543 & 0.05 & -0.313 & 0.57 & -2.971 & 0.00 & -2.597 & 0.38 \\
\hline \multicolumn{11}{|l|}{ Model 4} \\
\hline Secondary & -2.451 & 0.00 & -2.607 & 0.00 & -1.221 & 0.01 & -1.993 & 0.03 & -7.522 & 0.01 \\
\hline Secondary\& Student & 2.826 & 0.01 & 1.717 & 0.05 & 0.131 & 0.85 & 3.210 & 0.00 & -0.200 & 0.95 \\
\hline Secondary\& Student\& ViñedoViejo & -2.193 & 0.08 & -2.037 & 0.05 & -0.297 & 0.70 & -3.410 & 0.01 & -3.896 & 0.33 \\
\hline
\end{tabular}


and Environment but not for Relations. For example, in PhysicalHealth, girls with secondary education have a $245 \%$ worse assessment of physical health than girlswith university education. However, this percentage is reduced by $186 \%$ (to $59 \%$ ) if respondents have secondary education and are still students. Model 3 shows that the variable Secondary loses intensity for all health dimensions and has statistical significance for PhysicalHealth. Once again, the estimated value of Secondary for Relations is the most stable. For MentalHealth, PhysicalHealth and Environment the value of the interaction of education with residence zone is more important than educational level alone. For example, with PhysicalHealth, results show that girls with Secondary education who live in ViñedoViejo value their PhysicalHealth as $186 \%$ worse than girls with Secondary education living other areas. Finally, Model 4 confirms that in the study of the impact of education on the health of girl population groups, it is important to control for student status and residence zone.

Table 5 gives the regression coefficients of educational level for the state of health of boys living in Casablanca. The first notable result is that in Model 1 there is no evidence of the impact of education on the state of health of boys. However, the situation changes with Model 2 which shows that boys with Secondary education have lower levels of MentalHealth, Relations, Environment than men with university education, although this influence disappears for MentalHealth and Environment when the boys are students, in other words, the negative influence of having secondary education compared to university on health only remains for boys with secondary education who have already left the educational system. Model 3 does not provide any robust empirical evidence for boys. Model 4 confirms the results obtained in Model 2 for the MentalHealth and Environment.
Figure 2 is a compilation of previous results (Tables 4 and 5) illustrating visually the impact of education over health (Model 1) and how it is modulated when controlled by educational status (Model 2) and residence zone (Model 3). Each legend shows the educational impact controlling by the additional characteristics included in the legend, thus for example, the legend MenSecondary shows that boys with secondary education report a worst state of health for each category in relation to boys with university education, being the estimated coefficient the difference among both groups. Following this argumentation line MenSecondary\&NoStudent and MenSecondar$y \mathcal{E S t u d e n t}$ control prior results depending if the boys are still student or not. Then MenSecondary\&NoStudent report the additional impact of secondary versus university education for boys with secondary education that are no longer students. Gender differences reveal that girls 'state of health is more sensitive to education, student status and residence zone compared to boys.

\section{Discussion}

The results of this study show a clear relationship between a higher educational level and a higher level of HRQOL. This can be interpreted by means of materialistic theories that argue that the objective indicators of social class are also reflected in self-assessment and health indicators [21].

Although, in general, university students in the sample seem to enjoy a better health-related quality of life, this association is characterised by the fact that the sample was heterogeneous. $65 \%$ of the boys lived in Viñedo Viejo, compared to $59 \%$ of the girls and this might explain the differences observed in the student status. Distribution by educational level and residence zone was comparable: $54 \%$ of boys and $60 \%$ of girls who lived in

Table 5 Regression coefficients of educational level among young men living in Casablanca $(n=122)$

\begin{tabular}{|c|c|c|c|c|c|c|c|c|c|c|}
\hline & \multicolumn{2}{|c|}{ PhysicalHealth } & \multicolumn{2}{|c|}{ MentalHealth } & \multicolumn{2}{|l|}{ Relations } & \multicolumn{2}{|l|}{ Environment } & \multicolumn{2}{|l|}{ Total } \\
\hline & $\begin{array}{l}\text { Regression } \\
\text { coefficients }\end{array}$ & $p$-value & $\begin{array}{l}\text { Regression } \\
\text { coefficients }\end{array}$ & $p$-value & $\begin{array}{l}\text { Regression } \\
\text { coefficients }\end{array}$ & $p$-value & $\begin{array}{l}\text { Regression } \\
\text { coefficients }\end{array}$ & $p$-value & $\begin{array}{l}\text { Regression } \\
\text { coefficients }\end{array}$ & $p$-value \\
\hline \multicolumn{11}{|l|}{ Model 1} \\
\hline Secondary & -0.290 & 0.64 & -0.632 & 0.23 & -0.539 & 0.15 & -1.059 & 0.16 & -1.950 & 0.42 \\
\hline \multicolumn{11}{|l|}{ Model 2} \\
\hline Secondary & -1.052 & 0.16 & -1.623 & 0.01 & -0.912 & 0.04 & -2.505 & 0.01 & -5.221 & 0.08 \\
\hline Secondary\& Student & 1.421 & 0.08 & 1.847 & 0.01 & 0.713 & 0.15 & 2.691 & 0.01 & 6.100 & 0.06 \\
\hline \multicolumn{11}{|l|}{ Model 3} \\
\hline Secondary & -0.190 & 0.83 & -0.297 & 0.69 & -0.328 & 0.54 & -0.831 & 0.44 & -2.093 & 0.54 \\
\hline Secondary\& ViñedoViejo & -0.143 & 0.87 & -0.482 & 0.52 & -0.299 & 0.59 & -0.326 & 0.76 & 0.205 & 0.95 \\
\hline \multicolumn{11}{|l|}{ Model 4} \\
\hline Secondary & -1.052 & 0.16 & -1.623 & 0.01 & -0.912 & 0.05 & -2.505 & 0.01 & -5.221 & 0.08 \\
\hline Secondary\& Student & 1.219 & 0.21 & 1.858 & 0.02 & 0.617 & 0.32 & 2.833 & 0.02 & 4.715 & 0.23 \\
\hline Secondary\& Student\& ViñedoViejo & 0.395 & 0.72 & -0.020 & 0.98 & 0.181 & 0.79 & -0.269 & 0.84 & 2.696 & 0.54 \\
\hline
\end{tabular}


HRQL conditioned by education level

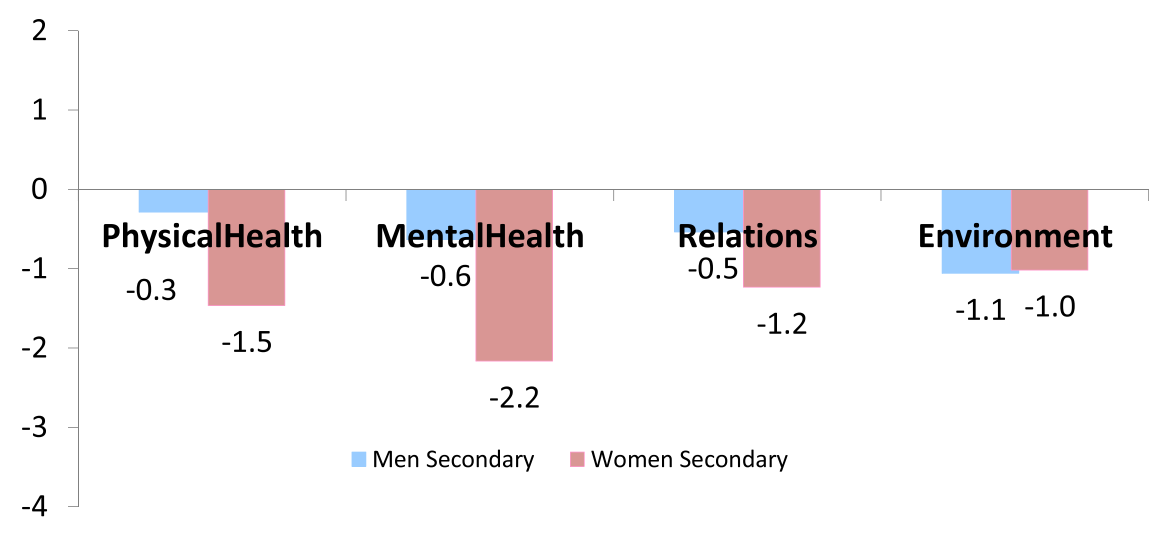

HRQL conditioned by educational level \& student status

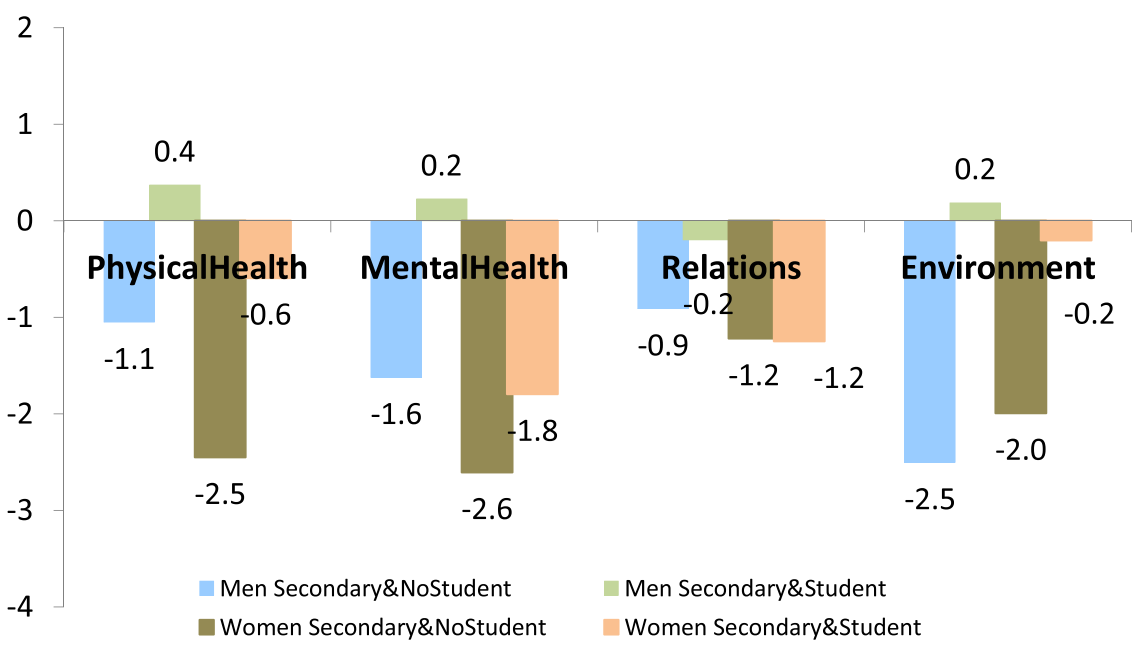

HRQL conditioned by educational level \& residential area

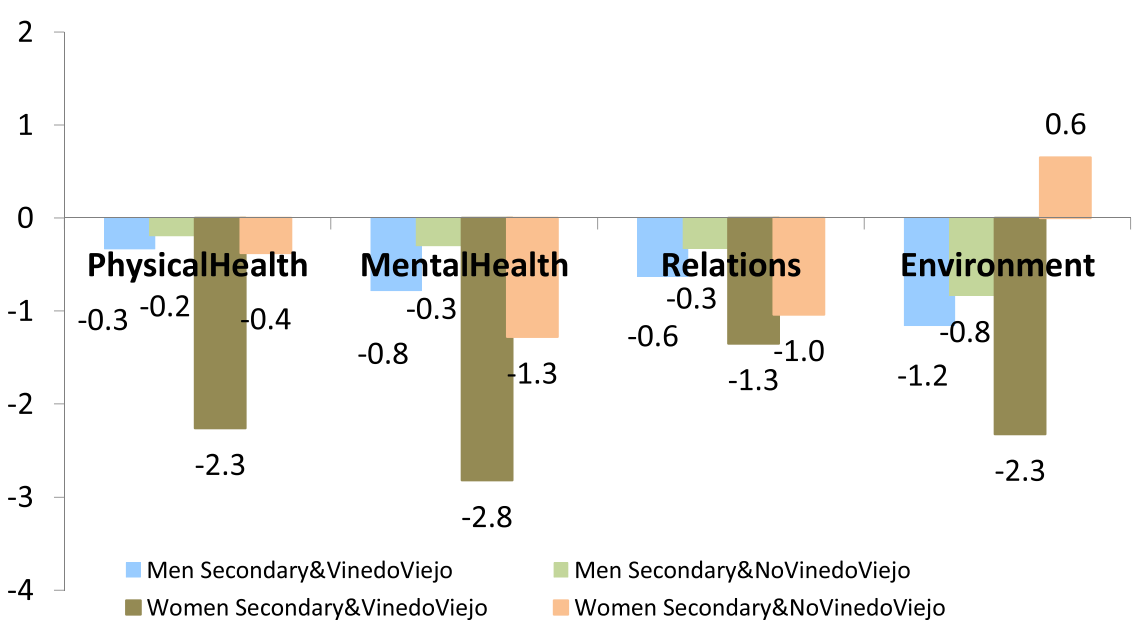

Fig. 2 Educational effects on HRQL dimensions 
Viñedo Viejo had secondary education but this result changes when student status is considered: just $43 \%$ of boys and $41 \%$ of girls who live in Viñedo Viejo and have secondary studies are still students - 10\% less than the average percentage for Casablanca as a whole.

Respondents with secondary education were those who gave a worse evaluation of the health of their environment. The age of the respondents may influence trends: the sample age range encompassed adolescence and youth, with their corresponding vital challenges. This finding is coherent with WHOQOL-BREF research by Saxena et al. [43] which compared adults and young people: adults prioritise environment and physical function; younger people prioritise their social domain.

Sex is a significant variable; it can be inferred that the level of education generates more differences among girls than boys. HRQOL was more sensitive to changes in educational level among girls than boys. These results confirm that women report lower states of health, but this may be due to the influence of factors related to gender roles men tend to complain less about their ailments and make less use of health services [20]. Differential gender attitudes of teachers, health professionals, parents and other social agents may also have an important influence. Gidley [55] argues that it may be the case that the education system is part of the inequity problem but it is definitely part of the solution: equity, pluralism and respect are values that can be taught and learnt in class.

The educational level had more specific weight in the four dimensions of HRQOL for girls. This was most notable for mental health [21]. It could be inferred that university education is a protective factor in the perceived quality of life of girls.

The fact that educational level, student status and residence zone have a joint influence on HRQOL of both boys and girls leads us to the stratification process. Among girls, the Physical and Environment dimensions were more important than Social and Residence (more than the educational level by itself). For boys, this interaction was evident in the Mental and Environment dimensions.

The results indicate that gender remains a significant source of inequality that should be taken into account in both the training of educational agents and health professionals [56]. It is a variable that influences identity, personal care and the use of health resources [57]. The persistence of significant statistical differences between boys and girls from Casablanca suggests that role models are still important [53].

\section{Limitations and strengths}

Age is a variable which may interact with educational level as the youngest participants of our sample are still school students therefore they have not had the chance to attend university. This is an issue that requires more in-depth research and a cohort perspective to analyze.

The study is cross-sectional and does not therefore consider the evolution of inequity. A longitudinal approach could provide information on the continuity of differences. In the same way, because this community research was conducted previous to the international economic crisis of 2007, an interesting future line of study is replying the study now, in order to capture tendencies and to measure the impact of this crisis.

The data is quantitative, research on perceptions, motivations or the evaluation of quality of life could be complemented by a qualitative methodology.

The main strength of this study is its local context. In addition to the use of national and international databases, information has been drawn from a specific community. The neighbourhood, as a place of residence and shared space, is the territorial unit closest to the configuration of healthy spaces. The results of the analysis can be used to generate programmes focused on the needs of the community, based on the principles of primary care and the promotion of citizen participation in education and health.

New lines of research arise from this work: young people grow up and develop in a family socioeconomic situation so it would be interesting to study how the level of education of the parents affects family lifestyles; the degree of aspiration and issues of gender differences are also of interest, the encouragement that parents, regardless of their level of education, give to their children to study and the extent to which they direct them towards learning and academic achievement.

\section{Conclusions}

A discussion on HRQOL and its association with education implies contemplation of the role of educational agents and instruction on lifestyles.

The results of this study illustrate the need for a set of social policies that:

- Increase equality of opportunities to access to higher education: there should be more scholarships and grants for students in unfavourable socioeconomic situations

- Improve informal education: the knowledge and skills acquired in non-academic contexts; in general, low socioeconomic contexts offer less health education and this increases exposure to risk factors. These inequalities should be addressed through prevention and awareness campaigns.

- Target young people and focus on health and education [58]. Health knowledge and the teaching of skills to minimise exposure to risk factors are of particular importance [28]. 
From a local and community perspective, the Casablanca Youth Centre, the Health Centre, schools and other institutions that are responsible for health and education in the community, could jointly instigate preventative instruction programmes for children and adolescents. In Spain, the Health Community Councils and Education Community Councils are legally responsible for this work which includes programmes on alcohol and drug abuse, sex education and road traffic safety. It also is clear that more attention must be paid to gender issues concerning the interactions between health perception, quality of life and wellbeing.

The results obtained in Casablanca suggest that it is necessary to consider the scope of intervention of local policies. The neighbourhood is the context where citizen participation in public health management can be fostered. Policies should aim to empower citizens by developing the role of health councils as the foundation of primary health care. The local environment favours direct participation: it is a relatively small space in which the institutions closest to young people are integrated - families, groups of friends, schools, health centres etc. [59].

\section{Supplementary information}

Supplementary information accompanies this paper at https://doi.org/10. 1186/s12955-020-01446-5.

Additional file 1: Table S1. Regression coefficients of educational level among young women living in Casablanca $(n=122)$ : models for physical health. Table S2. Regression coefficients of educational level among young women living in Casablanca $(n=122)$ : models for mental health. Table S3. Regression coefficients of educational level among young women living in Casablanca $(n=122)$ : models for relations. Table S4. Regression coefficients of educational level among young women living in Casablanca ( $n=122)$ : models for environment. Table S5. Regression coefficients of educational level among young women living in Casablanca ( $n=122)$ : models for total health. Table S6. Regression coefficients of educational level among young men living in Casablanca ( $n=122)$ : models for physical health. Table S7. Regression coefficients of educational level among young men living in Casablanca $(n=122)$ : models for mental health. Table S8. Regression coefficients of educational level among young men living in Casablanca $(n=122)$ : models for relations. Table S9. Regression coefficients of educational level among young men living in Casablanca $(n=122)$ : models for enviroment. Table S10. Regression coefficients of educational level among young men living in Casablanca $(n=122)$ : models for total.

\section{Abbreviations}

EQ-5D: EuroQol five dimensions scale; HRQOL: Health related quality of life; ISCED: International Standard Classification of Education; OLS: Ordinary Least Squares; SPSS: Statistical package for social sciences; STATA: Data analysis and statistical software; WHO: World Health Organization; WHOQOL: World Health Organization quality of life; WHOQOL-BREF: World Health Organization quality of life BREF test

\section{Acknowledgements}

Not applicable.

\section{Authors' contributions}

MG was the research director, field study and data revision. AG carried the method section and statistical analysis. LG revised the theoretical framework and conclusions. All authors read and approved the final manuscript

\section{Funding}

Ministerio de Economía y Competitividad (CSO2017-82110-R)

Gobierno de Aragón-Universidad de Zaragoza (Grupo de Referencia en Investigación, BYCS S16_17R)

Availability of data and materials

Please contact author for data request

Ethics approval and consent to participate

All procedures performed in this study were in accordance with the ethical standards of the Zaragoza University and with the 1964 Helsinki Declaration and its later amendments.

Subjects were informed about the research and signed an informed consent prior to the survey. The data treatment was anonymous.

\section{Consent for publication}

Not applicable.

\section{Competing interests}

The authors declare that they have no competing interests.

\section{Author details}

${ }^{1}$ Department of Psychology and Sociology, Health Science Faculty, Domingo Miral s/n, 50009 Zaragoza, Spain. ${ }^{2}$ Department of Management, School of Engineering and Architecture, C. María de Luna, 3, Edificio Betancourt, Campus Río Ebro, 50018 Zaragoza, Spain. ${ }^{3}$ Department of Psychology and Sociology, Social and Work Science Faculty, Violante de Hungria 23, 50009 Zaragoza, Spain

Received: 18 April 2018 Accepted: 9 June 2020

Published online: 16 June 2020

\section{References}

1. Barayan SS, Al Dabal BK, Abdelwahab MM, Shafey MM, Al Omar RS. Healthrelated quality of life among female university students in Dammam district: is internet use related? J Fam Community Med. 2018;25:20-8.

2. Klein JT. Prospects for transdisciplinarity. Futures. 2004;36(4):515-26.

3. Hassanzadeh J, Asadi-Lari M, Baghbanian A, Ghaem H, Kassani A, Rezaianzadeh A. Association between social capital, health-related quality of life, and mental health: a structural-equation modeling approach. Croat Med J. 2016;57(1):58-65.

4. Cox RG, Zhang L, Johnson WD, Bender DR. Academic performance and substance use: findings from a state survey of public high school students. Sch Health. 2007;77(3):109-15.

5. Mayet A, Legleye S, Falissard B, Chau N. Cannabis use stages as predictors of subsequent initiation with other illicit drugs among French adolescents: use of a multi-state model. Addict Behav. 2012:37(2):160-6.

6. Henning MA, Hawken SJ, Krägeloh C, Zhao Y, Doherty I. Asian medical students: quality of life and motivation to learn. Asia Pac Educ Rev. 2011; 12(3):437-45.

7. Pichler F. Subjective quality of life of young Europeans. Feeling happy but who knows why? Soc Indic Res. 2006;75(3):419-44

8. United Nations. Constitution of the World Health Organization. 2012. http:// apps.who.int/gb/bd/PDF/bd47/EN/constitution-en.pdf. Accessed 24 July 2019.

9. Albert C, Davia M. Salud, salarios y educación [health, wages and finnances]. Hacienda Pública Esp. 2004;169(2):11-34.

10. Michel G, Bisegger C, Fuhr DC, Abel T. Age and gender differences in health-related quality of life of children and adolescents in Europe: a multilevel analysis. Qual Life Res. 2009;18(9):1147-57.

11. Burström K, Johannesson M, Rehnberg C. Deteriorating health status in Stockholm 1998-2002: results from repeated population surveys using the EQ-5D. Qual Life Res. 2007;16(9):1547-53.

12. Jörngården $A$, Wettergen $L$, von Essen L. Measuring health-related quality of life in adolescents and young adults: Swedish normative data for the SF-36 and the HADS, and the influence of age, gender, and method of administration. Health Qual Life Outcomes. 2006;1(4):91.

13. Kristjánsdóttir J, Sundelin C, Naessen T. Health-related self-assessed quality of life in young people at a Youth Centre in Sweden. Scand J Caring Sci. 2009;23(3):465-72 
14. Tuesca-Molina R, Centeno-Romero H, de la Ossa-Salgado M, García-Delgado N, Lobo-López J. Calidad de vida relacionada con la salud y determinantes sociodemográficos en adolescentes de Barranquilla (Colombia) [Quality of life related to health and sociodemographic determinants in adolescents from Barranquilla (Colombia)]. Salud Uninorte. 2008;24(1):53-63.

15. World Health Organization. Inequalities in young people's health: health behaviour in school-aged children. Copenhagen: World Health Organization Regional Office for Europe; 2008.

16. Vohra J, Marmot MG, Bauld L, Hiatt RA. Socioeconomic position in childhood and cancer in adulthood: a rapid-review. J Epidemiol Community Health. 2016;70(6):629-34.

17. Cockerham WC. Sociología de la medicina [Sociology of Medicine]. Madrid: Prentice Hall; 2002

18. Darias-Curvo S. Determinantes socioeconómicos y salud en Canarias: el caso de los factores de riesgo cardiovascular [Socioeconomic determinants and health in the Canary Islands: the case of cardiovascular risk factors]. Ph.D thesis. Universidad de La Laguna, Servicio de Publicaciones. 2011. https://www.researchgate.net/profile/ Sara_Darias-Curvo/publication/320004425 Determinantes socieconomicos_y_salud_en_Canarias_el_caso_de_los_factores_de_ riesgo_cardiovascular/links/59cba6380f7e9bbfdc3b68bb/Determinantessocieconomicos-y-salud-en-Canarias-el-caso-de-los-factores-de-riesgocardiovascular.pdf. Accessed 4 May 2020.

19. Rodríguez-Díaz IC. Análisis de la Clase Social como determinante de salud en la población adulta de Canarias [Analysis of social class as a determinant of health in the adult population of Canary Islands]. Ph.D. thesis. Servicio de Publicaciones, Universidad de La Laguna. 2011. https://absysnetweb.bbtk.ull. es/cgi-bin/abnetopac/O7069/ID19657ad5?ACC=131\&srch=\%222011\%22. FEPU.\&xsface $=0 n \&$ etapaFace $=1$ \&fieldFace=FEPU. Accessed 4 May 2020

20. Souto S. Percepción de la salud: determinantes sociales en la atención primaria [Self-rated health: Social determinants in community health]. Ph.D. thesis. Universidad de la Coruña, Servicio de publicaciones. 2012; https://ruc. udc.es/dspace/handle/2183/12446. Accessed 4 May 2020.

21. Sanz A. Estudiar importa: El nivel de estudios y la salud en la juventud [Studying matters: The level of studies and health in youth]. Master thesis in Sociology of Public and Social Policies. University of Zaragoza. 2016; https:// zaguan.unizar.es/record/56409?!n=es. Accessed 4 May 2020.

22. Buck D, Frosini F. Clustering of unhealthy behaviours over time. London: The Kings Fund; 2012.

23. Wilkinson RG, Pickett KE. Income inequality and social dysfunction. Annu Rev Sociol. 2009:35(1):493-511.

24. Buon T, Compton B. Credentials, credentialism and employee selection. Asia Pac J Hum Resour. 1990;28(4):126-32 https://doi.org/10.1177/ 103841119002800413.

25. Burton-Jeangros C, Cullati S, Sacker L, Blane D. A life course perspective on health trajectories and transitions. New York: Springer; 2015.

26. Hooftman WE, Westerman MJ, Van Der Beek AJ, Bongers PM, Van Mechelen W. What makes men and women with musculoskeletal complaints decide they are too sick to work? Scand J Work Environ Health. 2008:34(2):107-12.

27. Gil-Lacruz M. Psicología social: un compromiso aplicado a la salud [Social psychology: an applied commitment to health]. Zaragoza: Prensas de la Universidad de Zaragoza; 2007.

28. Gil-Lacruz M. Health-related quality of life in youth. Definition, dimensions and research difficulties. In: Henning MA, Krägeloh CU, Wong-Toi G, editors. Student motivation and quality of life in higher education. London: Routledge; 2015. p. 73-81.

29. De Maeyer J, Vanderplasschen W, Lammertyn J, van Nieuwenhuizen C, Broekaert E. Exploratory study on domain-specific determinants of opiatedependent individuals' quality of life. Eur Addict Res. 2011;17(4):198-210.

30. De Maeyer J, Vanderplasschen W, Broekaert E. Exploratory study on drug users' perspectives on quality of life: more than health-related quality of life? Soc Indic Res. 2009;90(1):107-26.

31. Becker SJ, Curry JF, Yang C. Factors that influence trajectories of change in frequency of substance use and quality of life among adolescents receiving a brief intervention. J Subst Abus Treat. 2011;41(3):294-304.

32. Golubović Š, Škrbić R. Agreement in quality of life assessment between adolescents with intellectual disability and their parents. Res Dev Disabil. 2013;34(6):1863-9.

33. Wallander JL, Schmitt M, Koot HM. Quality of life measurement in children and adolescents: issues, instruments, and applications. J Clin Psychol. 2001; 57(4):571-85.
34. Weitkamp K, Daniels JK, Romer G, Wiegand-Grefe S. Health-related quality of life of children and adolescents with mental disorders. Health Qual Life Outcomes. 2013;11(1):129.

35. Skevington SM, Lotfy M, O'Connell KA. The World Health Organization's WHOQOL-BREF quality of life assessment: psychometric properties and results of the international field trial. A report from the WHOQOL group. Qual Life Res. 2004;13(2):299-310.

36. Whoqol Group. The World Health Organization quality of life assessment (WHOQOL): position paper from the World Health Organization. Soc Sci Med. 1995;41(10):1403-9.

37. McHorney CA. Health status assessment methods for adults: past accomplishments and future challenges. Annu Rev Public Health. 1999;20(1): 309-35.

38. Whogol Group. Development of the World Health Organization WHOQOLBREF quality of life assessment. Psychol Med. 1998;28(3):551-8.

39. Cilga İ. Research on students' quality of life and risky living conditions. Eurasian J Educ Res. 2010;38(10):55-70.

40. Li K, Kay NS, Nokkaew N. The performance of the World Health Organization's WHOQOL-BREF in assessing the quality of life of Thai college students. Soc Indic Res. 2009;90(3):489-501.

41. Krägeloh CU, Henning M, Hawken SJ, Zhao Y, Shepherd D, Billington R. Validation of the WHOQOL-BREF quality of life questionnaire for use with medical students. Educ Health. 2011;24(2):545.

42. Zhang Y, Qu B, Lun S, Wang D, Guo Y, Liu J. Quality of life of medical students in China: a study using the WHOQOL-BREF. PLoS One. 2012;7(11): e49714.

43. Saxena S, Carlson D, Billington R, Orley J. The WHO quality of life assessment instrument (WHOQOL-BREF): the importance of its items for cross-cultural research. Qual Life Res. 2001;10(8):711-21.

44. Mannert K, Dehning S, Krause D, Leitner B, Rieder G, Siebeck M, Tesfaye M, Abera M, Hailesilassie H, Tesfay K, Jobst A. Quality of life in Ethiopia's street youth at a rehabilitation center and the association with trauma. J Trauma Stress. 2014;27(5):593-601.

45. Van Damme L, Colins O, De Maeyer J, Vermeiren R, Vanderplasschen W. Girls' quality of life prior to detention in relation to psychiatric disorders, trauma exposure and socioeconomic status. Qual Life Res. 2015;24(6):1419-29.

46. Chen $Y Y$, Huang $\mathrm{JH}$. Precollege and in-college bullying experiences and health-related quality of life among college students. Pediatrics. 2015;135(1): $18-25$.

47. Izutsu T, Tsutsumi A, Islam AM, Kato S, Wakai S, Kurita H. Mental health, quality of life, and nutritional status of adolescents in Dhaka, Bangladesh: comparison between an urban slum and a non-slum area. Soc Sci Med. 2006;63(6):1477-88.

48. Zullig KJ, Valois RF, Huebner ES, Drane JW. Adolescent health-related quality of life and perceived satisfaction with life. Qual Life Res. 2005; 14(6):1573-84.

49. Wardle J, Steptoe A, Guliš G, Sartory G, Sêk H, Todorova I, Vögele C, Ziarko M. Depression, perceived control, and life satisfaction in university students from Central-Eastern and Western Europe. Int J Behav Med. 2004;11(1):27-36.

50. Chipuer HM, Bramston P, Pretty G. Determinants of subjective quality of life among rural adolescents: a developmental perspective. Soc Indic Res. 2003; 61(1):79-95.

51. Schiff $M$, Nebe $S$, Gilman R. Life satisfaction among Israeli youth in residential treatment care. Br J Soc Work. 2005;36(8):1325-43.

52. Baumann M, Ionescu I, Chau N. Psychological quality of life and its association with academic employability skills among newlyregistered students from three European faculties. BMC Psychiatry. 2011:11:63.

53. Gil-Lacruz M, Gil-Lacruz Al. Health-related quality of life in a sample of young people in Spain. In: Henning MA, Krägeloh CU, Wong-Toi G, editors. Student motivation and quality of life in higher education. London: Routledge; 2015. p. 82-9.

54. Institute for Statistics. International standard classification of education. Montreal: UNESCO, Institute for Statistics; 2012.

55. Gidley JM. Futures of education for rapid global-societal change. In: González F, editor. There's a future: visions for a better world. 2012:5:395419. Madrid: BBVA; 2012. p. 63-73.

56. Nachreiner F. Diversity and equity: dealing with biological and social differences. Rev Saude Publica. 2004;38(Suppl):80-5. 
57. Noone JH, Stephens C. Men, masculine identities, and health care utilisation. Sociol Health III. 2008;30(5):711-25.

58. World Health Organization. Health for the world's adolescents. Geneva: WHO; 2014.

59. Mawson E, Best D, Beckwith M, Dingle GA, Lubman DI. Social identity, social networks and recovery capital in emerging adulthood: a pilot study. Subst Abuse Treat Policy. 2015;10:45.

\section{Publisher's Note}

Springer Nature remains neutral with regard to jurisdictional claims in published maps and institutional affiliations.

Ready to submit your research? Choose BMC and benefit from:

- fast, convenient online submission

- thorough peer review by experienced researchers in your field

- rapid publication on acceptance

- support for research data, including large and complex data types

- gold Open Access which fosters wider collaboration and increased citations

- maximum visibility for your research: over $100 \mathrm{M}$ website views per year

At $\mathrm{BMC}$, research is always in progress.

Learn more biomedcentral.com/submissions 